\title{
Impacto da Inserção de Tecnologias Digitais na Formação Inicial de Professores de Matemática Egressos de uma Universidade Pública Federal
}

\author{
Denice Aparecida Fontana Nisxota Menegais, PGIE/ UFRGS, denice.menegais@gmail.com \\ Léa da Cruz Fagundes, PGIE/ UFRGS, leafagundes@ufrgs.br \\ Laurete Zanol Sauer, UCS, lzsauer2@gmail.com
}

\begin{abstract}
Resumo: Este artigo é um recorte de uma pesquisa que está em desenvolvimento no doutoramento em Informática na Educação. Para tanto, foi realizada, em um primeiro momento, uma análise da disciplina Tecnologias Aplicadas ao Ensino de Matemática, presente no Projeto Político Pedagógico do Curso de Licenciatura em Matemática de uma Instituicão de Ensino Superior do Rio Grande do Sul. A intenção foi compreender a influência das tecnologias na formação dos professores. Em continuação, um grupo de egressos de tal curso de licenciatura participou da pesquisa, que consistiu na aplicação de um questionário com o objetivo de investigar de que modo estes profissionais fazem uso das tecnologias na prática docente. De maneira geral, as análises sinalizaram que as disciplinas voltadas ao uso pedagógico das tecnologias, em particular a disciplina de Tecnologias Aplicadas ao Ensino de Matemática, foram muito importantes para a formação inicial dos professores, mas não se mostraram suficientes para o uso efetivo nas práticas em sala de aula.
\end{abstract}

Palavras-Chave: Formação de Professores de Matemática; Tecnologias Digitais; Aprendizagem de Matemática na Educação Básica.

Abstract: Abstract: This article is part of a research that is under development at $\mathrm{PhD}$ in Informatics in Education. Therefore, it was held, at first, an analysis of discipline Applied Technologies in Teaching Mathematics, present in Political Pedagogical Project's Degree in Mathematics of an Institution of Higher Education of Rio Grande do Sul. The intent was to understand the influence of technologies in teacher training. In continuation, a group of graduates from this course participated in the survey, which consisted of a questionnaire aiming to investigate how these professionals make use of technology in teaching. In general, the analyzes signaled that subjects focused on pedagogical use of technology, particularly the discipline of Technologies Applied to the Teaching of Mathematics, were very important for the initial training of teachers, but were not sufficient for effective use in practice in the classroom.

Keywords: Training of Teachers of Mathematics; Digital technologies; Learning Mathematics in Basic Education.

\section{Introdução}

As tecnologias digitais estão cada vez mais presentes no ambiente escolar. No entanto, integrá-las ao cotidiano pedagógico da escola torna-se um grande desafio para as instituições educacionais, assim como para os professores, pois essa integração requer mudanças na prática pedagógica. Desse modo, entende-se que o ensino, de maneira geral, deve privilegiar a aprendizagem baseada na construção do conhecimento, 
contemplando os interesses dos estudantes, e na apropriação de recursos tecnológicos, visando sua aplicação em atividades que desenvolvam competências importantes para sua formação (MENEGAIS et al, 2013).

Diante dessa realidade, é importante que os professores explorem atividades em que sejam utilizados recursos tecnológicos capazes de contextualizar a realidade do estudante, procurando proporcionar uma aprendizagem mais ativa, uma vez que os conteúdos de Matemática não estão presentes somente na vida escolar, mas no cotidiano como um todo. Nesse sentido, as instituições educacionais necessitam mudar para atender os estudantes de hoje, tidos como nativos digitais ${ }^{1}$ e pertencentes à geração Homo Zappiens $^{2}$, preparando-os para o exercício da cidadania (BRASIL, 1997). Com isso, ressalta-se que o uso das tecnologias digitais, integradas às práticas pedagógicas, pode ser um dos elementos capazes de melhorar a aprendizagem de Matemática na atual Sociedade em Rede (CASTELLS, 2003). O presente estudo, portanto, tem como objetivo investigar como os egressos do curso de licenciatura em Matemática foram preparados para o uso das Tecnologias de Informação e Comunicação (TIC) nos processos de ensino e aprendizagem de Matemática, e de que modo estes sujeitos fazem uso pedagógico das tecnologias na prática docente.

Diante dessas considerações, inicialmente, discute-se a importância da formação inicial de professores, tendo em vista a inclusão das TIC nas práticas docentes. Na seção 2, analisa-se o projeto político pedagógico do curso de licenciatura em Matemática da universidade. Na seção 3, apresenta-se a análise dos questionários aplicados aos professores de Matemática egressos do curso de licenciatura. Finalizando, na seção 4, apresentam-se algumas considerações em relação ao uso das TIC na formação inicial dos educadores, bem como sua aplicação no contexto escolar.

\section{Inserção das TIC na Formação Inicial de Professores de Matemática}

Com base nos estudos realizados, a introdução das tecnologias digitais no cotidiano da sala de aula requer uma ampla e profunda revisão na formação dos professores, visto que a simples presença das tecnologias no ambiente escolar, por si só, não parece ser suficiente para que ocorram mudanças significativas na prática pedagógica (MENEGAIS, et al, 2013). De acordo com Papert (2008, p. 76):

[...] Em muitos sistemas escolares, o que é oferecido como preparo aos professores que usarão os computadores é com muita propriedade denominado treinamento, pois consiste em um pequeno número de sessões de duas horas erroneamente chamadas de workshops ou seminários, cuja meta é transmitir habilidades técnicas.

\footnotetext{
${ }^{1}$ Para os "nativos digitais”, as tecnologias digitais “estão sempre presentes, imbricadas nas suas ações, eles vivem e pensam com essas tecnologias. Elas estão na forma como eles se comunicam, se relacionam com os demais sujeitos e com o mundo, fazem parte das experiências construídas no seu viver e conviver.” (Schlemmer, 2006, p. 34-35).

${ }^{2}$ Homo zappiens é a nova geração que aprendeu a lidar com as novas tecnologias, sendo aquela que
cresceu usando múltiplos recursos tecnológicos desde a infância. Esses recursos permitiram a esses
indivíduos ter controle sobre o fluxo de informações, mesclando comunidades virtuais e reais,
proporcionando uma comunicação imediata e colaborando em rede, de acordo com suas necessidades. O
Homo zappiens é um processador ativo de informação que resolve problemas de maneira muito hábil,
usando estratégias de jogos, e que sabe se comunicar com eficiência. Sua relação com a escola mudou
profundamente, pois “[...] o Homo zappiens é digital e a escola é analógica.” (Veen, Vrakking, 2009).
}

V. $12 \mathrm{~N}^{\mathrm{o}} 2$, julho, 2014 
Nessa perspectiva, Papert (2008) sugere que, ao invés de apenas “treinar” os professores utilizando-se de habilidades técnicas, é necessário que eles desenvolvam estratégias que provoquem mudanças pedagógicas profundas e que sejam benéficas aos estudantes. O papel do professor, ao ensinar em uma sociedade da informação, é muito mais do que "treinar" os estudantes para o uso das tecnologias digitais: é estar aberto a indagações, curiosidades e desafios, além de procurar compreender o processo de aprendizagem dos seus estudantes. É necessário, pois, que o professor crie situações relevantes com o uso das TIC, que sejam aliadas às práticas pedagógicas e passíveis de uma aprendizagem ativa, sempre levando em consideração o contexto da cultura digital em que estão inseridos os aprendizes e respeitando os ritmos e as características individuais, a fim de que o uso do computador, efetivamente, provoque mudanças pedagógicas, ou seja, que considere as tecnologias como recursos para pensar e aprender, e não apenas promover a alfabetização em informática. Assim, entende-se, assim como Richit e Maltempi (2010, p. 27), que:

\begin{abstract}
[...] mudanças na estrutura curricular dos cursos de licenciatura tornam-se necessárias, de modo que o conhecimento específico seja valorizado, mas que não seja o fim único da formação inicial docente. Para tanto, entendemos que a construção do conhecimento matemático deve acontecer de forma contextualizada, ou seja, entrelaçada às demais atividades formativas do licenciando, usando recursos diversos, incluindo as tecnologias, e no âmbito de diferentes situações de sala de aula, isto é, de docência.
\end{abstract}

Diante desse contexto, é fundamental que os futuros professores tenham acesso a uma formação que priorize a inserção das tecnologias digitais no cotidiano da sala de aula de forma intensiva; partindo de uma proposta de inovação curricular que focalize as atividades nos interesses dos estudantes, faz-se necessário estimular a capacidade de reflexão e argumentação, considerando tais aspectos, como agentes ativos e fundamentais para o processo de aprendizagem.

\title{
2. TIC na Matriz Curricular do Curso de Licenciatura em Matemática
}

O Curso de Licenciatura em Matemática da Universidade, criado em 2006, tem como objetivo formar professores de Matemática para atuar na educação básica (séries finais do Ensino Fundamental e Ensino Médio). Espera-se, desta forma, que o profissional adquira o domínio do conhecimento matemático, bem como, esteja em condições para a continuação de seus estudos em nível de pós-graduação. A criação do curso de Matemática foi justificada a partir da necessidade de suprir a carência de professores especializados na área para atender à demanda das escolas da região. Em relação ao perfil do egresso, percebe-se que o curso de Licenciatura em Matemática destaca algumas competências/habilidades que o futuro professor deverá desenvolver durante a graduação. Dentre elas, destaca-se:

O engajamento num processo de contínuo aprimoramento profissional, procurando sempre atualizar seus conhecimentos com abertura para a incorporação do uso de novas tecnologias e para adaptar o seu trabalho às 
novas demandas sócio-culturais e dos alunos (Projeto Político Pedagógico do Curso, 2009, p. 11).

No que diz respeito às competências e às habilidades, os professores responsáveis pela formação dos futuros profissionais da área de Matemática devem ter clareza suficiente, para que, além da apropriação das tecnologias digitais como recursos didáticos com os quais irão trabalhar, precisam saber integrar esta metodologia ao currículo da educação básica, de modo a promover mudanças significativas na prática pedagógica e, consequentemente, nos processos de construção do conhecimento dos estudantes.

Atualmente, o Curso de Licenciatura em Matemática conta com salas de aula, Laboratório de informática, Biblioteca, Sala de apoio para atendimento aos estudantes, Laboratório de Matemática Computacional, Laboratório Multimídia e Laboratório de Educação Matemática. Além desses laboratórios, estão previstos outros dois: o Laboratório de Projetos e Monitoria e o Laboratório de Tecnologias de Ensino de Matemática. O curso é oferecido no período noturno e tem duração mínima de quatro anos, organizados em oito semestres, perfazendo um total de 2810 horas/aula e compreendendo 420 horas de estágio supervisionado, 435 horas de prática ao longo do curso, 60 horas em atividades à distância, 1695 horas em atividades teóricas e 200 horas em atividades complementares, conforme Resolução do Conselho Nacional de Educação - CNE/CP 02/2002, resultante do Parecer CNE/CP 28/2001. O ingresso no curso se dá pelo Sistema de Seleção Unificada (SISU), proposto pelo Ministério da Educação, que se utiliza das notas obtidas pelos estudantes no ENEM (Exame Nacional do Ensino Médio). A carga horária universitária está distribuída em 30 disciplinas obrigatórias, 05 disciplinas optativas, 02 disciplinas de estágio de observação supervisionado e 02 disciplinas de estágio supervisionado; além das disciplinas oferecidas, o curso oferece, a cada semestre, o mínimo de 25 horas de atividades complementares, como, por exemplo, semanas acadêmicas, mostras de trabalhos resultantes das observações realizadas nas disciplinas de estágio, entre outras práticas.

Observa-se, no currículo do curso, que apenas a disciplina Tecnologias Aplicadas ao Ensino de Matemática trata de conhecimentos relacionados às tecnologias, que possui carga horária de 04 horas/aula semanais, contabilizando 30 horas práticas e 30 teóricas, sendo a disciplina ofertada aos estudantes do curso no quarto semestre e podendo contemplar as seguintes temáticas: I) Conhecimentos básicos de informática; II) Análise e discussão de aplicativos de informática para o ensino de Matemática na educação básica e no ensino profissionalizante; III) Calculadoras e multimídia para educação básica; e IV) Planejamento, execução e análise de aulas experimentais de Matemática utilizando as tecnologias aplicadas ao Ensino Fundamental e Médio. Na proposta curricular da disciplina, é possível observar que o conteúdo é bastante extenso para ser executado em apenas 4 créditos, cabendo aos professores formadores decidirem quais recursos tecnológicos serão priorizados; ao mesmo tempo, com a metade da sua carga horária prática, ela proporciona ao futuro docente, a elaboração e a execução de atividades de Matemática utilizando as tecnologias, o que promove a articulação entre a teoria e a prática no âmbito do curso e a integração dessas atividades com as escolas da educação básica . Afinal, o professor continua sendo aquele que planeja e desenvolve situações de ensino, com base no conhecimento que possui sobre determinado conteúdo, sobre os processos de aprendizagem, sobre a didática das disciplinas e sobre a potencialidade da ferramenta tecnológica como um recurso para promover a aprendizagem. 
Desde a implantação do curso, modificações foram sendo incorporadas em seu currículo a fim de que ele atenda às necessidades da educação atual. Na nova versão do Projeto Político Pedagógico do curso, aprovada no primeiro semestre de 2014, a disciplina Tecnologias Aplicadas ao Ensino de Matemática passou a ser de caráter opcional, sendo ofertada a partir da demanda dos estudantes. Faz parte obrigatória do currículo a disciplina Softwares na Aprendizagem de Matemática, com carga horária de 04 horas/aula semanais, o que contabiliza 15 horas práticas e 45 teóricas. Ela é ofertada no primeiro semestre do curso e visa ao estudo e à discussão de conteúdos da educação básica a partir da utilização de softwares destinados ao ensino e à aprendizagem de Matemática, contemplando conteúdos como funções, geometria, entre outros. Ao término da disciplina de Softwares, espera-se que o futuro professor adquira conhecimentos suficientes para elaborar e implementar sequências didáticas de conteúdos de Matemática na educação básica, utilizando softwares como recursos pedagógicos. Além disso, é de suma importância que o estudante do curso de Matemática reflita e discuta a utilização e os impactos das tecnologias no processo de ensino-aprendizagem, tomando consciência quanto à importância dos conhecimentos apreendidos na disciplina Tecnologias Aplicadas ao Ensino de Matemática, em função desta ser opcional no currículo do curso. Reconhece-se, todavia, a inclusão da disciplina Softwares como um avanço em relação à inserção das tecnologias digitais no curso de Licenciatura em Matemática. No entanto, diante dos avanços tecnológicos da atual "Sociedade da Informação”, ou "Sociedade do Conhecimento", é relevante que o futuro professor entre em contato com as tecnologias enquanto recursos didáticos a serem utilizados em vários momentos de sua formação, ou seja, nas diversas disciplinas que integram o currículo do curso. Deste modo, busca-se cumprir as diretrizes das Licenciaturas em Matemática, as quais preveem que, desde o início do curso, os discentes apropriem-se das tecnologias digitais como parte dos processos didáticos a serem usados nas futuras práticas pedagógicas. A análise do curso corrobora com os estudos de Richit (2005), os quais indicam que os cursos de Licenciatura em Matemática carecem de uma "revisão em seus currículos de modo que o aprendizado específico destes recursos não se resuma apenas a noções elementares de uso, desenvolvidas em disciplinas estanques de um semestre letivo.” (p. 49).

Na próxima seção é apresentada a análise da pesquisa, que visou investigar, por meio de entrevistas, como os egressos do curso de licenciatura em Matemática estão utilizando as TIC nas suas práticas docentes.

\section{As Tecnologias Digitais e a Prática Docente de Professores de Matemática}

Com o objetivo de investigar como os egressos do curso de Licenciatura em Matemática foram preparados para o uso das TIC no processo de aprendizagem da área em questão, foi aplicado um questionário para melhor compreendermos as formas pelas quais se deu este processo, uma vez que essa sondagem visou investigar de que modo os professores atuantes da rede pública da região fazem uso pedagógico das tecnologias na prática docente. Nesse sentido, é apresentada uma breve caracterização dos profissionais participantes da pesquisa. Destaca-se, portanto, que o questionário foi aplicado a oito professores, sendo que todos retornaram respondidos.

Os professores ingressaram no curso de Licenciatura em Matemática em 2006, 2007, 2008 e 2009, concluindo-o entre os anos de 2010 e 2013. Estão atuando, além disso, como professores da disciplina de Matemática nas séries finais do ensino fundamental (do $6^{\circ}$ ao $9^{\circ}$ ano), no ensino médio, no ensino técnico e no ensino superior. 
Quanto ao tempo de atuação em sala de aula, os professores, que têm entre 23 e 41 anos, trabalham nessa área há mais de 6 meses.

Considerando a importância da formação continuada, questionou-se sobre a participação dos professores em programas dessa natureza, após a conclusão do curso de licenciatura. Mais da metade dos professores afirmaram, então, que participaram ou estão participando de algum curso de formação nesse nível, índice considerado positivo, já que os professores concluíram o curso de licenciatura há pouco tempo. O professor A concluiu o curso de especialização em "Estudos Matemáticos - Ênfase em Ensino de Matemática” pelo Instituto de Física e Matemática da Universidade Federal de Pelotas (UFPel) e está cursando o Mestrado pelo Programa de Pós-Graduação em Ensino de Ciências e Matemática na mesma instituição. O professor B atualmente participa do curso "Pacto pelo ensino médio". Já o professor C participa da formação continuada "Projovem Urbano de Bagé”. A professora D concluiu a especialização em Supervisão e Orientação Educacional e, assim como os docentes B e H, está participando do curso "Pacto pelo ensino médio". Os oito professores participantes da pesquisa são identificados como A, B, C, D, E, F, G e H, conforme mencionados.

Uma das perguntas do questionário referiu-se à existência do Laboratório de Informática nas escolas em que atuam e se os computadores estão conectados à internet. Todos os profissionais responderam que nas escolas em que atuam há Laboratório de Informática; destes, apenas na escola do professor D os computadores não estão conectados à internet. Quando questionados se a escola em que lecionam foi contemplada com o Programa "Um Computador por Aluno" (PROUCA), 100\% afirmou que não.

Quanto à utilização dos computadores nas aulas de Matemática como um recurso de apoio ao ensino, 50 \% dos professores afirmaram utilizar; 37,5\% não utilizam e 12,5\% não responderam (conforme análise apresentada no Quadro 1). O professor A respondeu utilizar o recurso duas vezes por semana para apresentações em Power Point e plotagem de gráficos; já o professor C utiliza uma vez por semana para apresentações de conceitos e vídeos matemáticos; os professores B e D responderam utilizá-lo em atividades que envolvam os conteúdos tradicionais trabalhados, porém sem uma frequência definida; os professores E, F e H responderam que não utilizam e a professora $\mathrm{G}$ não respondeu.

Quadro 1 - Utilização dos computadores nas aulas de Matemática

\begin{tabular}{ll}
\hline Opções & Porcentagem \\
\hline Sim & $50 \%$ \\
Não & $37,5 \%$ \\
Não responderam & $12,5 \%$ \\
Total & $100 \%$ \\
\hline
\end{tabular}

Em relação às disciplinas mais citadas do curso de Licenciatura em Matemática que utilizaram as tecnologias, durante o período de aula $100 \%$ dos professores afirmaram fazer uso do recurso na disciplina de Tecnologias Aplicadas ao Ensino de Matemática ${ }^{3}$; 37,5\% dos docentes tiveram contato com as mesmas em "Laboratório de Ensino de Matemática II” (professores B, G e H); 25\%, na disciplina de Laboratório de Matemática I (professores G e H); e 25\% em "Estágio no Ensino Fundamental e Médio” (professores B e C). A partir dos depoimentos, foi possível perceber que as disciplinas

${ }^{3}$ De acordo com a análise realizada no currículo do curso, é a única disciplina que trata de conhecimentos relativos às tecnologias. 
do curso que utilizaram as tecnologias no período de aula foram trabalhadas de forma superficial e isoladas das demais, pois apenas os docentes B, C e D afirmaram que a formação que tiveram no curso de Licenciatura em Matemática em relação ao uso pedagógico das Tecnologias da Informação e Comunicação (TIC) foi suficiente para a utilização destas na sua prática educativa. Os educadores A, E, F e H responderam que a formação obtida no curso não foi suficiente para a utilização das tecnologias na prática docente. Para melhor compreensão, seguem abaixo trechos das narrativas dos sujeitos entrevistados via questionário:

\begin{tabular}{|l|l|}
\hline Prof. A & $\begin{array}{l}\text { Não, pois a formação em relação às TIC focou mais na existência e na } \\
\text { importância dessas tecnologias. Penso que faltaram momentos de } \\
\text { obtenção de conhecimento técnico propriamente dito para que os } \\
\text { graduandos pudessem utilizar logo no início de sua prática docente. }\end{array}$ \\
\hline Prof. E & $\begin{array}{l}\text { Não, conheci vários programas computacionais para uso de gráficos, e } \\
\text { só. Em que situações usá-las e como lidar com a manifestação dos alunos } \\
\text { frente ao uso das TIC nunca foi trabalhado. Ou seja, conheço diversos } \\
\text { softwares, mas não conheço situações propícias para aplicá-los de forma } \\
\text { produtiva em sala de aula. }\end{array}$ \\
\hline Prof. F & $\begin{array}{l}\text { Não, pois na grade curricular havia apenas uma disciplina relacionada } \\
\text { com tecnologias e não foi possível explorar apropriadamente. }\end{array}$ \\
\hline Prof. H & Não. Não consigo obter e realizar atividades com TIC. \\
\hline
\end{tabular}

Por fim, os professores foram questionados quanto àquilo que consideram importante durante o planejamento de atividades via computador:

\begin{tabular}{|c|l|}
\hline Prof. A & $\begin{array}{l}\text { Delinear com clareza o objetivo principal da atividade e a } \\
\text { possibilidade de o aluno usar somente o computador, não } \\
\text { necessitando, por exemplo, do registro em papel. }\end{array}$ \\
\hline Prof. B & $\begin{array}{l}\text { No caso da escola onde trabalho é ter consciências que nem todos têm } \\
\text { domínio, mesmo que básico, dos computadores. Também devemos } \\
\text { prever situações fora de comum, que podem acontecer e dar liberdade } \\
\text { para os alunos experimentarem e testarem outras formas para a a } \\
\text { resolução de atividades. }\end{array}$ \\
\hline Prof. C & $\begin{array}{l}\text { Ter o domínio do conteúdo e da tecnologia que está propondo aos } \\
\text { alunos. }\end{array}$ \\
\hline Prof. D & $\begin{array}{l}\text { Aplicar uma atividade que tenha um sentido pedagógico, que tenha a } \\
\text { ver com o conteúdo trabalhado em sala de aula e que traga uma } \\
\text { contribuição para a formação do aluno. }\end{array}$ \\
\hline Prof. E & Seria preciso colocar mais em prática a interação e a ação dos alunos. \\
\hline Prof. F & Não respondeu. \\
\hline Prof. G & $\begin{array}{l}\text { É importante, primeiro, saber se os alunos possuem um conhecimento } \\
\text { básico de informática e, segundo, é saber qual o benefício que aquela } \\
\text { atividade irá trazer na construção do conhecimento. }\end{array}$ \\
\hline Prof. H & $\begin{array}{l}\text { Que seja elaborado um roteiro para os alunos e que nele contenha as } \\
\text { atividades e o método de avaliação destas. }\end{array}$ \\
\hline
\end{tabular}

Pode-se observar que os professores têm consciência da importância do planejamento de atividades que considerem o uso das tecnologias como recurso para aprender e pensar Matemática, e não apenas visam centrar as tarefas no uso da máquina. 
Consideram a importância de ter domínio do conteúdo proposto e da tecnologia a ser utilizada pelos estudantes, procurando, nas atividades desenvolvidas com o uso do computador, compatibilidade com o nível de aprendizagem dos alunos e com o tempo necessário e adequado para a realização das atividades.

\section{Análise e Discussão}

De maneira geral, a análise das respostas do questionário sinalizou que as disciplinas voltadas ao uso pedagógico das tecnologias, em particular a disciplina de Tecnologias Aplicadas ao Ensino de Matemática, foram muito importantes para a formação inicial dos professores. Todavia, não bastou utilizar os recursos tecnológicos durante o período de graduação para que ocorresse o uso eficaz e efetivo destes procedimentos na prática docente. Foi diagnosticado, quando questionados sobre os recursos pedagógicos que costumam utilizar com mais frequência nas escolas, que $50 \%$ dos professores utilizam o livro didático e materiais impressos, este último nos mostrando uma apuração de 37,5\% dos professores. A análise confirma que nas instituições educacionais, assim como refere Kenski (1996, p. 136) "formam-se professores sem um conhecimento mais aprofundado sobre a utilização e manipulação de tecnologias educacionais e sentem-se inseguros para utilizá-las em suas aulas”, pois o livro didático e o material impresso continuam sendo a "fonte de informações", por assim dizer, mais usada na sala de aula. Diante do exposto, ações devem ser implementadas, tendo em vista o uso pedagógico das tecnologias digitais na aprendizagem de Matemática, fato que ressalta a importância de cursos de formação continuada para os professores.

\section{Considerações Finais}

A análise da proposta de pesquisa, que envolveu a análise do projeto político pedagógico do Curso de Licenciatura em Matemática da universidade considerada, sinalizou que a formação inicial para o uso das tecnologias digitais no processo de ensino e aprendizagem não foram suficientes para o uso efetivo destas, constatação que pode ser observada no depoimento de uma das professoras quando questionada sobre a suficiência da formação inicial para a utilização das TIC na sala de aula: "Não, pois na grade curricular havia apenas uma disciplina relacionada com tecnologias e não foi possível explorar apropriadamente”. Essa realidade corrobora com a pesquisa realizada pelo Centro de Estudos da Fundação Victor Civita (FVC) junto ao Ibope e ao Laboratório de Sistemas Integráveis da Universidade de São Paulo (LSI-USP), em 2009, concluindo que, em 400 escolas de treze capitais, $72 \%$ dos entrevistados consideraram a formação inicial oferecida no curso de graduação insuficiente e inadequada para o uso das tecnologias na prática docente, pois faltava preparo para o uso deste recurso, visto que o foco do ensino dos conteúdos continua sendo o currículo escolar tradicional. Essa questão também é evidenciada por Almeida (2000), que sugere que, nos cursos de graduação, os profissionais formadores estão, por assim dizer, presos em suas práticas e distantes de novas abordagens pedagógicas, principalmente no que se refere ao uso de recursos tecnológicos. Nesse sentido, é de suma importância que os professores tenham a oportunidade de participar de cursos de formação continuada que integrem as tecnologias digitais no contexto do ambiente escolar, proporcionando momentos de reflexão e discussão sobre o fazer pedagógico, que os habilite a participar, com qualidade, da Sociedade em Rede, da qual os estudantes já participam. 


\section{Referências}

ALMEIDA, M. E. B. de. O Computador na Escola: Contextualizando a Formação de Professores. Praticar a teoria, refletir a prática. São Paulo, 2000. Tese de Doutorado em Educação. Programa de Pós Graduação em Educação: Supervisão e Currículo, Pontifícia Universidade Católica de São Paulo.

BRASIL. Ministério da Educação. Secretaria de Educação Fundamental. Parâmetros Curriculares Nacionais: Matemática $\left(1^{\circ}\right.$ e $2^{\circ}$ ciclos do ensino fundamental). v. 3. Brasília: MEC/ SEF, 1997.

CASTELLS, M. A. A galáxia na internet: reflexões sobre a internet, os negócios e a sociedade. Tradução de Maria Luíza X. de A. Borges. Rio de Janeiro: Jorge Zahar, 2003.

FVC- Fundação Vitor Civita (2009). O uso dos computadores e da Internet nas escolas públicas de capitais brasileiras. Disponível em: <www.fvc.org.br/estudos>. Acesso em: 29 de julho de 2014.

MENEGAIS, D. A. F. N.; PESCADOR, C. M.; FAGUNDES, L. da C. Práticas Pedagógicas em Matemática: experiências em uma escola do Programa UCA. In: RENOTE - Revista Novas Tecnologias na Educação, v. 11, n. 1, 2013.

PAPERT, S. A máquina das crianças: repensando a escola na era da informática. Tradução de Sandra Costa. Porto Alegre: Artmed, 2008. 224p.

RICHIT, Adriana. Projetos em Geometria Analítica Usando Software de Geometria Dinâmica: repensando a Formação Inicial Docente em Matemática. 2005. 215 f. Dissertação (Mestrado em Educação Matemática) - Instituto de Geociências e Ciências Exatas, Universidade Estadual Paulista, Rio Claro, 2005.

RICHIT, A.; MALTEMPI, M. V. Desafios e Possibilidades do Trabalho com Projetos e com tecnologias na Licenciatura em Matemática. ZETETIKÉ - FE Unicamp - v. 18,n. $33-$ jan/jun - 2010. Disponível em: http://www.fe.unicamp.br/zetetike/viewarticle.php?id=474\&layout=abstract. Acesso em: 18 fev. 2012.

SCHLEMMER, E. O trabalho do professor e as novas tecnologias. Textual, Porto Alegre, v. 1, n. 8, p. 33-42, $2006 . \quad$ Disponível em: http://www.sinprors.org.br/textual/set06/artigo_tecnologia.pdf

VEEN, W.; VRAKKING, B. Homo zappiens: educando na era digital. Porto Alegre: Artmed, 2009.

KENSKI, V.M. O Ensino e os recursos didáticos em uma sociedade cheia de tecnologias. In: VEIGA, I.P.A. (org). Didática: o Ensino e suas relações. Campinas, SP: Papirus, 1996. 